\title{
rendimiento comparativo de los pavimentos de hormigón y de los revestimientos asfálticos en las autopistas norteamericanas
}

\begin{abstract}
Este artículo constituye un resumen de un estudio publicado en la revista "Travaux" en febrero de 1961, habiéndose omitido las re. ferencias a la situación en Francia que dicho estudio contenía, y traducido a pesetas las cifras que figuraban en dólares.
\end{abstract}

Parece necesario dar a conocer los resultados de las estadísticas efectuadas por el Gobierno federal de los Estados Unidos de Norteamérica sobre los tres puntos siguientes:

- examen comparado de la duración de las carreteras con pavimentación de hormigón y con pavimentación asfáltica;

- comparación del coste anual del entretenimiento de ambos tipos de pavimentación;

- comparación del coste total del entretenimiento ordinario y extraordinario de ambos tipos de pavimento, a lo largo del período de treinta y cinco años.

Conviene observar que, en los Estados Unidos, más del $70 \%$ de las autopistas de gran tráfico tienen pavimento de hormigón; no sólo las construídas por el Estado, sino también las carreteras de peaje, en las que los problemas de coste y duración a largo plazo tienen una importancia fundamental.

\section{d La prueba del tiempo}

El Estado de Michigán cuenta con un total de $14.800 \mathrm{~km}$ de carreteras, de los cuales 5.000 van con pavimento de hormigón y 3.200 tienen pavimento mixto, de asfalto sobre base de hormigón. Las primeras carreteras de hormigón se construyeron en 1909, y la mayoría llevan en servicio trein- 

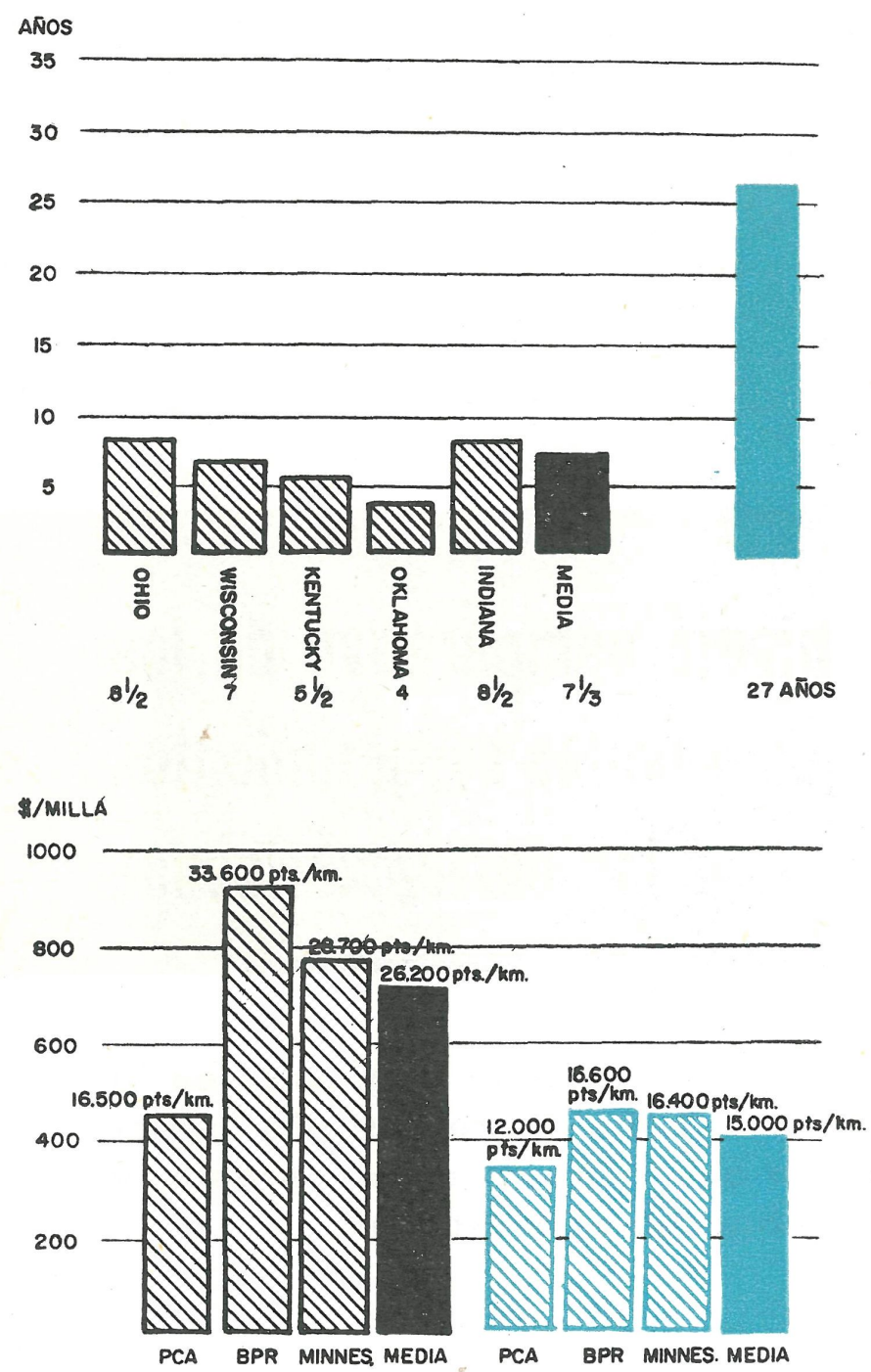

Fig. 1.-Período de servicio de un revestimiente asfáltico y un pavimento de hormigón.

PCA BPR MINNES MEDIA

PCA BPR MINNES. MEDIA

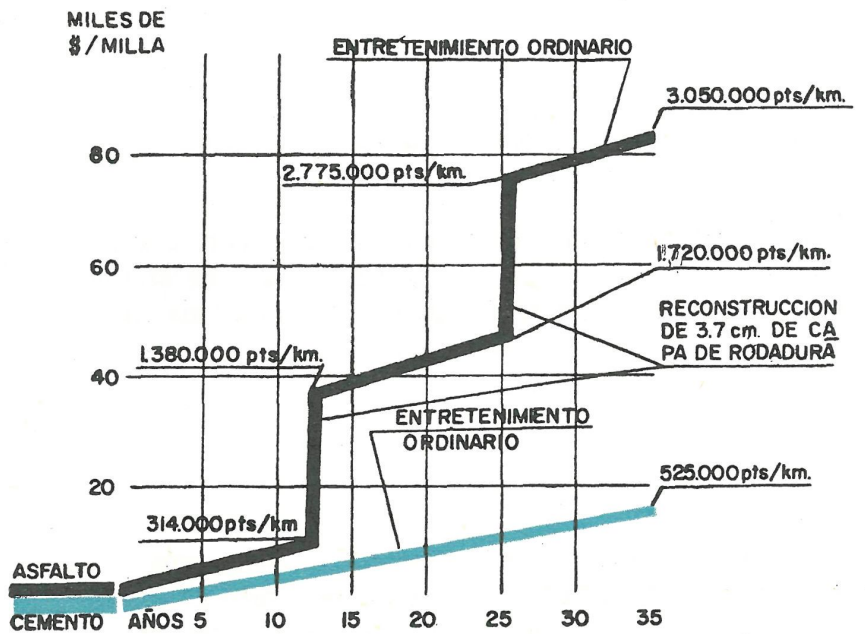

Fig. 2.-Comparación del coste anual del entretenimiento de autopista de cuatro vías de circulación, con pavimento asfáltico y pavimento de hormigón

Fig. 3.-Comparación del coste acumulado del entretenimiento de una autopista de cuatro vías de circulación, con pavimento asfáltico y pavimento de hormigón 
ta y cinco y cuarenta años; no obstante, soportan todavía el aumento de tráfico y cargas que se les impone en la actualidad. Las construídas recientemente, con materiales y técnicas mejoradas, durarán más de cincuenta años.

En la figura 1 se expresa claramente la duración del servicio de la carretera de hormigón, netamente superior a todo otro tipo de pavimento: veintisiete años como media, sin necesidad de retoques, y teniendo en cuenta que el aumento del tráfico no estuvo previsto cuando se proyectaron las carreteras antiguas. Por el contrario, los firmes flexibles en las autopistas de tráfico pesado de Ohio, Indiana, Wisconsin, Oklahoma y Kentucky presentan una duración media de siete años y medio, pasados los cuales hay que reconstruirlos. Incluso la famosa «New Jersey Turnpike» ha necesitado, al cabo de ocho años, una reparación cuyo coste unitario ha excedido el correspondiente a la construcción.

\section{Comporación del coste anual del entretenimiento de pavimen- tos asfálticos y de hormigón}

Aunque se conozca con detalle el coste de construcción de una carretera, rara vez se efectúa el estudio del coste del entretenimiento necesario para mantenerla en servicio; sin embargo, este último con frecuencia excede al primero.

El conocimiento del coste de entretenimiento es tan importante como el conocimiento de la duración del servicio de una carretera. De un estudio efectuado por el Bureau of Public Roads sobre más de $16.000 \mathrm{~km}$ de carreteras con diversas pavimentaciones, se desprende que el gasto anual en conservación y entretenimiento alcanza a $905 \$$ por milla $(33.600$ ptas $/ \mathrm{km})$ en pavimentos flexibles sometidos a tráfico intenso; frente a $446 \$$ por milla de pavimento de hormigón (16.600 pesetas/kilómetro). Análogos resultados ha dado un estudio efectuado en el Estado de Minnesota por el Departamento de Carreteras.

En la figura 2 se aprecian los resultados de las estadisticas antedichas y, asimismo, otra de la Portland Cement Association; el resultado medio es que el coste del entretenimiento anual de un firme flexible es doble del de un firme de hormigón.

\section{Comparación del cosie total de entretenimiento y reparación en 35 años, para pavimentos flexibles y de hormigón}

El coste real de una carretera no está únicamente determinado por el de la construcción del firme. Por ejemplo, en el Estado de Michigán, el coste de construcción de una carretera con pavimento de hormigón es menor que el de la misma carretera con pavimento asfáltico, debido a que los firmes flexibles para tráfico pesado necesitan una costosa preparación de la subrasante y el establecimiento de varias capas de base.

Además, incluso en los casos en que pueda parecer más barato inicialmente establecer un pavimento asfáltico, la presunta economía es anulada rápidamente por el mayor gasto de conservación y la frecuente reconstrucción de la capa de rodadura (a intervalos de cinco a ocho años, por lo general).

En la figura $3 \mathrm{~s}$ ecomparan, gráficamente, los costes totales de entretenimiento y reparación de una milla de carretera de cuatro circulaciones durante treinta y cinco años, supuesto que el firme asfáltico se reconstruye cada doce-trece años. Al cabo de los treinta y cinco años el pavimento de hormigón estará todavía en buen estado, y sólo habrá requerido 14.140 \$ por milla ( 525.000 pesetas/kilómetro) en gastos de conservación; frente a $81.910 \$(3.050 .000 \mathrm{ptas} / \mathrm{km})$ para el firme asfáltico; realizándose una economía neta de $2.525 .000 \mathrm{ptas} / \mathrm{km}$. 


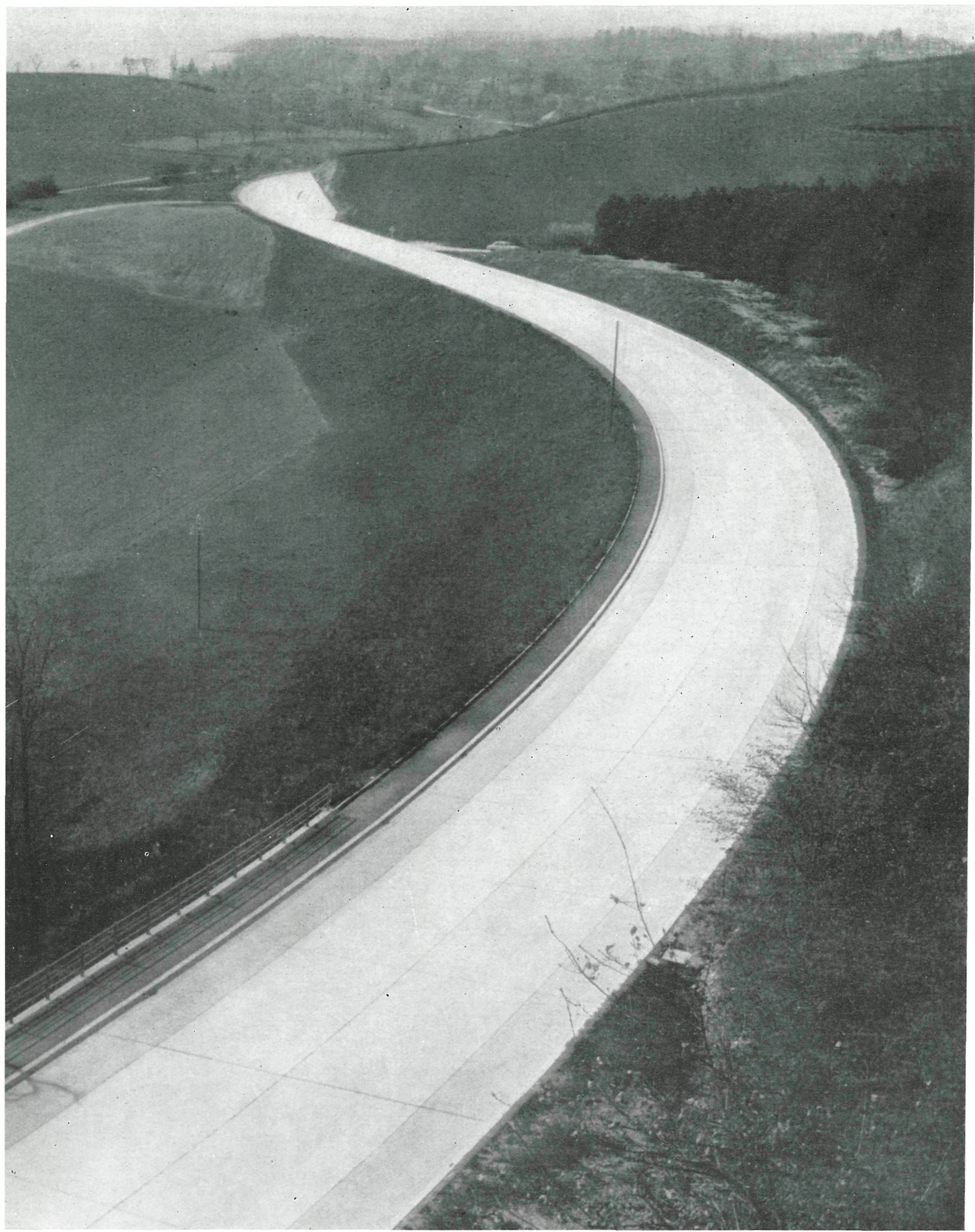

\section{firmes blaneos}

Los firmes blancos de hormigón permiten conseguir calzadas de rodadura inmejorable, y mediante el empleo de áridos de diferentes colores se consiguen efectos estéticos de notables calidades y que, a la vez, permiten resolver problemas funcionales, como ocurre en este tramo de carretera en el que la zona central, blanca, se destaca bordeada por las pistas laterales, para ciclistas, rojas. 